\title{
The Relationship of Age to Level of Performance and Independence Associated with Rehabilitative Interventions Provided to Older Adults Who Are Blind
}

\author{
Michael Brooks ${ }^{1} \&$ Barry C. Stephens ${ }^{1}$ \\ ${ }^{1}$ North Carolina A\&T State University, USA \\ Correspondence: Michael Brooks, North Carolina A\&T State University, USA
}

Received: July 1, 2014

Accepted: July 18, $2014 \quad$ Available online: August 8, 2014

doi:10.11114/ijsss.v2i4.454

URL: http://dx.doi.org/10.11114/ijsss.v2i4.454

\begin{abstract}
The purpose of this study was to investigate the relationship between rehabilitative interventions and older adults with visual impairments. This study employed an ex post facto, quasi-experimental design which analyzed changes that occurred based on composite pretest and posttest scores representing levels of performance and independence. Participants were visually impaired adults, age 65 and above, who successfully completed a rehabilitation program intended to increase their skills for independent living. A repeated measures multivariate analysis of variance (MANOVA) was conducted to determine if there were significant improvements on pretest to posttest levels of performance and independence derived from the rehabilitative interventions, and if improvements were related to age. Statistically significant gains were noted on overall performance and independence for both the ADL and IADL domains.
\end{abstract}

Keywords: Rehabilitation interventions, older adults, blindness

\section{Introduction}

The Relationship of age to Level of Performance and Independence Associated with Rehabilitative Interventions Provided to Older Adults who are blind

Projections indicate that by the year 2030, there will be close to 9 million severely visually impaired persons in the age 65 and older cohort (Crews, 1994; Zambelli-Weiner, A., Crews, J. E., \& Friedman, D. S., 2012). Prevalence of vision loss among the oldest-old cohort, those 85 years of age or older, is expected to grow dramatically. Among the three recognized cohorts within the older population, those 65 to 74 years, those 75 to 84 years, and those 85 years and above, the oldest-old are the most at risk for vision loss with rates of severe visual impairment as high as one in four (Crews, 1994; Zambelli-Weiner, A., Crews, J. E., \& Friedman, D. S., 2012).

Over a typical lifespan, most individuals will experience some form of visual impairment, which will interfere with activities of daily living or require some form of treatment (Kline \& Schieber, 1985). Age-related vision loss, one of the most common and potentially disabling late life conditions, affects approximately $13 \%$ of all older adults living in the community (NCHS, 2013). According to a survey by the American Optometric Association, nearly one-third of the elderly with visual impairments reported an inability to perform household chores and engage in recreational activities (DiStefano \& Aston, 1986). Thirty percent reported difficulty reading the newspaper, and $40 \%$ noted problems going up and down stairs. All individuals age 60 and older experienced a reduction in near vision due to age-related changes in the eye. Moreover, these typical impairments related to age-related vision changes adversely affected social and psychological happiness (DiStefano \& Aston, 1986).

More than half of all adults with vision loss agree that visual impairment interferes with what they want to do in their daily lives. Although most in this group of adults are highly similar in their diagnoses, they respond to the conditions of aging and vision loss in a highly individualized manner (The Lighthouse Inc., 1995). A person's experience with any disabling condition is not an isolated event; there are numerous environmental factors which influence possible responses to loss (Hendricks, 1992). Both human and material resources are fundamental elements that are an undeniable part of an individual's physical and psychosocial response to late-life disability. In this context, individuals with disabilities bring with them a diverse set of challenges with complex implications for families, communities, and 
ultimately a nation. In the sense that disability threatens an individual's identity, self-esteem, and quality of life, disability threatens the fiber of the human community as a whole (Hendricks, 1992; Zarit, 1992).

The field of rehabilitation and the field of aging do not necessarily define functional independence in the same terms and may, therefore, measure levels of functioning differently (Mann, Hurren, Tomita, \& Charvat, 1995). The most universally accepted delineation of functional independence is associated with the aggregate tasks domains known as activities of daily living (ADLs) and instrumental activities of daily living (IADLs) commonly found in the literature on aging. Not only have ADLs and IADLs been well defined in the literature, but numerous scales have been constructed to discriminate among various levels of functioning within these domains (Aiken, 1995; Katz, 1983; Katz \& Stroud, 1989; Lawton, 1991; Orr, 1992). In previous studies, ADL and IADL levels of impairment have been gauged in relation to an individual's ability to independently perform tasks within the respective domains (Katz \& Stroud, 1989; Lawton, 1991). The level of task performance and the level of independence of performance are the primary considerations in assessing ADL and IADL impairment.

The ADLs encompass seven basic personal care tasks: bathing, eating, grooming, dressing, toileting, transferring (from lying to sitting, sitting to standing, and the reverse activity), and walking (Katz, 1983; Lawton, 1991). The IADLs represent a hierarchy beyond basic hygiene and health, focusing instead on tasks thought to be necessary for a person to live independently in the community. The IADL tasks include meal preparation, use of the telephone, home management activities, money management, shopping, laundry, housework, and mobility outside of the home (Furner, Rudberg, \& Cassel, 1995; Katz, 1983; Lawton, 1991). Independent living programs that serve elders who are blind most often focus on IADL concerns (Nieuwenhuijsen, Frey, \& Crews, 1991).

The ADLs and IADLs are not isolated elements within the life of an individual who is visually impaired. Levels of dependence and control are related to psychosocial stability (Zarit, 1992). The results of a recent study of adults with visual impairments confirmed that higher self-esteem is significantly related to lower levels of dependence on others for the performance of daily living tasks (Beach, Robinet, \& Hakim-Larson, 1995).

Some noted gerontologists view dependence and independence on a continuum. This view holds that levels of dependence and independence are in a constant state of fluidity throughout lifespan developmental stages (Motenko \& Greenberg, 1995). Baltes (1996) asserts that late-life dependencies are qualitatively different from those of childhood and middle adulthood and as such, late-life dependencies may be characterized in terms of mutually enhancing reciprocal relationships with shared responsibilities. Perhaps the distinguishing characteristic of these late-life dependencies is that they are based on mutually autonomous preferences, and therefore, may be termed interdependencies, which maintain the dignity and self-worth of participating parties.

Baltes (1996) wrote of late life dependencies as normal and valuable for many people who are aging. Her research indicated that, in some cases, dependent behaviors may be initiated to provide social contact because independent behaviors may not prompt responses from social partners. Baltes referred to these two response patterns as dependency-support scripts and independence-ignore scripts. She emphasized that conscious choices related to particular levels of dependence are often efficacious and a natural part of late life development.

Thus, Baltes (1996) postulated that the socially learned scripts related to various levels of dependence are highly functional and adaptive and, in some instances, do not reflect loss but rather gain (in control over social contact). Her concept of "selective optimization with compensation" must be taken into account in relation to any discussion of human dependency. Regardless of Baltes' view, generally our society views dependence negatively, evidenced by the fact that both medical and functional rehabilitation models are specifically oriented to reduce dependence and promote independence (Kemp, Brummel-Smith, \& Ramsdell, 1990).

Among older adults with visual impairments who have received rehabilitation services under Title VII, Chapter 2 (VII-2) of the Rehabilitation Act, little is known about changes that occur related to ADLs and IADLs. Among this population, neither levels of performance or independence have been analyzed in terms of these domains (Crews, 1991; Stephens, Lai, \& Giesen, 1997).

Because little research has been conducted involving VII-2 program participants, several questions remain unaddressed in the literature. Do services that are targeted to improve the functional ability of older adults who are visually impaired affect their level of performance or independence on either ADL or IADL tasks? Do older program participants, who are more likely to experience multiple disabling conditions, have comparable outcomes to those who are younger? The focus of this study will be on the relationship between chronological age and the pretest to posttest levels of change that occur on performance and independence among the daily living tasks associated with ADLs and IADLs.

The review of literature for this study revealed no analysis of VII-2 data has been conducted on more than one state program at a time. Additionally, no analysis within the current body of literature has occurred that considers the various 
demographic variables associated with program participants. In this study, specific demographic variables will be reported and discussed to enrich an understanding of derived outcomes. No VII-2 outcome data have been found which analyze the effectiveness of services provided upon the older end of the age spectrum, where multiple disabilities are more likely to exist. This study will investigate differences in outcomes based upon age.

The purpose of this study, which focuses upon older people with visual impairments, is to determine the relationship between chronological age, rehabilitative interventions, and changes in levels of ADL and IADL performance and independence. The significance of rehabilitative interventions will be determined based upon pretest to posttest changes in the levels of performance and independence exhibited on ADLs and IADLs. The results of this study will contribute to the limited quantity of research and knowledge that currently exists.

The research questions to be addressed are as follows:

1). Do older adults in different age groups, who complete a rehabilitation program designed for those who are severely visually impaired, exhibit statistically significant gains in their level of performance on Activities of Daily Living $(\mathrm{ADL})$ ?

2). Do older adults in different age groups, who complete a rehabilitation program designed for those who are severely visually impaired, exhibit statistically significant gains in their level of independence on Activities of Daily Living (ADL)?

3). Do older adults in different age groups, who complete a rehabilitation program designed for those who are severely visually impaired, exhibit statistically significant gains in their level of performance on Instrumental Activities of Daily Living (IADL)?

4). Do older adults in different age groups, who complete a rehabilitation program designed for those who are severely visually impaired, exhibit statistically significant gains in their level of independence on Instrumental Activities of Daily Living (IADL)?

\section{Methodology}

This study employed an ex post facto quasi-experimental design. The treatment provided was a rehabilitation program offered by agencies that work with individuals who are blind. These rehabilitation programs are designed to facilitate improvements in the levels of performance and independence of daily living tasks associated with independent living and adjustment to blindness. This study analyzed pretest to posttest changes that occurred among the three age categories in the context of ADL performance and independence and IADL performance and independence. According to Borg and Gall (1989), "The one group pretest-posttest design is especially appropriate when you are attempting to change a behavior pattern or internal process that is very stable" (p. 672). Among older adults those behavior patterns defined, as levels of performance and independence often remain stable except when losses occur that are due to physical impairments. Vision loss and other physical impairments are likely to reduce one's level of performance and independence if rehabilitative interventions are not available.

The dependent variables in this study were the differences in the pretest to posttest levels of performance and independence among the three age groups on ADL and IADL. The treatment, which was provided for all subjects, was the completion of a rehabilitation program designed to enhance the independent living skills of senior adults who are blind. The degree to which rehabilitative interventions influenced the composite level of ADL and IADL performance and ADL and IADL independence, by age category, was the focus. The independent variable, age was defined by three categories based on common age groupings found in the literature and in U.S. census data (Aiken, 1995; Cox, 1996; Hooyman \& Kiyak, 1993; National Center for Health Statistics, 1998; and Orr, 1992). Subjects were classified into the following discrete chronological age categories: 65-74 years, 75-84 years, and 85 or more years. Delineation of these particular age categories makes it possible for the results of this study to be considered along with other studies that have used these same categories. Demographic information was reported on each age category in order to determine any pre-existing bias.

The instrument used for measuring levels of performance and independence in this study was the Independent Living Pre Program Assessment and Independent Living Post Program Assessment (ILPPA). This instrument utilizes a rating scale that was adapted to a logical ordinal hierarchy. Four levels of task performance were delineated based on the existing rating scale. Three levels of task independence were delineated by aggregation across seven original categories.

\subsection{Instrumentation}

The ILPPA was used to gather pre and post data regarding levels of performance and independence for ADL and IADL tasks. This instrument has been used more than any other in the field of blindness to gather data on those participating in independent living programs (P. Rogers, personal communication, March 14, 1997). Its development and refinement 
over the past twelve years, as previously outlined, have made it the most widely accepted protocol for outcome measurement for the population being studied.

The ILPPA measures pre and post levels of performance and independence on 41 specific daily living tasks. Although designed primarily to measure daily living tasks associated with adjustment to blindness, many of these tasks are closely associated with the more readily identified domains of ADL and IADL.

The ILPPA is primarily a domain-referenced instrument developed within the arenas of aging and independent living rehabilitation programs for individuals who are blind. Rehabilitation specialists established face validity when the instrument was created by the careful selection of items for assessment that deal specifically with behaviors critical to daily living activities (Nieuwenhuijsen, et al., 1991). Content validity has been ascertained throughout the history of the instrument. Rehabilitation specialists using the ILPPA as a primary assessment tool in their independent living programs have provided feedback to program administrators and researchers (Nieuwenhuijsen, et al., 1991; Stephens, Lai, \& Giesen, 1997). Limited revisions to the instrument have been based on a study of sub-scale reliability and factorial validity conducted by Cancienne (1989) and feedback received by the RRTC-BLV from rehabilitation teachers using the instrument in the field. The factor analysis of items used to evaluate task performance and independence determined that some items were redundant (Cancienne, 1989). Therefore, some items were eliminated resulting in a reduced scale that was more user friendly yet equally discriminating. Content and construct validity are evidenced by the instrument's inclusion of tasks delineated throughout the literature as related to ADL and IADL domains.

The ILPPA rating scale for independence is confounded due to the lack of clear delineation between some of the elements of the scale; therefore, an aggregated version of the scale was used for the purposes of this study. Face validity of the aggregated scale was achieved via deliberations among research scientists at the Rehabilitation Research and Training Center on Blindness and Low Vision. The aggregated three point scale used to determine the level of independence was: 3 = autonomous (alone or aided by device), 2 = human assisted (human assisted/dependent, human augmented, or human hired), and $1=$ non-performance (no desire or unable to perform task). Although some discretionary data was obscured due to the aggregation of some options on the original scale, this adapted aggregated scale affords a measure, which delineates an underlying continuous dimension of independence.

The ILPPA has some additional features beyond the capacity to gather pre and post data on performance and independence that contributed to the richness of this study. The pre and post program form of the ILPPA also contain sections for recording information related to participant characteristics, environmental factors, and the types of services provided. These categories of descriptive data are reported as a part of the overall demographic profile derived from the database used in this study.

\subsection{Selection of the Population}

The population selected for this study was all VII-2 program participants, age 65 and older, who were administered the pretest and posttest ILPPA during the Federal Government fiscal years (FY) 1995 and 1996. Data were gathered on all of these program participants using the most recently revised version of the ILPPA. Random sampling among the existing national programs was not possible because less than twenty programs have gathered pretest and posttest data, and only six states have collected such data using the ILPPA since its most recent revision during the past two years. Therefore, the population in this study is comprised of all VII-2 program participants for whom pretest and posttest data on the revised ILPPA are available from FY:95 and FY:96. Demographic data from the participants studied is presented in this report so that similarities and differences with demographic data from the national population can be noted. The total $\underline{\mathrm{N}}$ for the population in this study was 1,194 . The $\underline{\mathrm{n}}$ contributed per program breaks down as follows: Arkansas, 377; Georgia, 32; Idaho, 104; Kentucky, 16; Tennessee, 110; and Virginia, 555.

The reasons for choosing this particular population were: (a) these programs represented the four primary models of service provision for independent living programs serving older individuals who are blind; (b) collectively these programs exhibited a demographic profile similar to the national program average (Stephens, 1996; Stephens \& Lai, 1997a, 1997b, 1997c, 1997d); (c) the staff in each of these programs were trained by the same researcher in the use of the instrument, thereby helping to enhance inter-observer reliability and consistency in the process of the collection of data; and (d) these are the only programs that have used the latest revision of the ILPPA.

\section{Procedures.}

The ILPPA was administered prior to service delivery and re-administered subsequent to program completion. Rehabilitation teachers who completed the ILPPA received training from the RRTC-BLV principal investigator. As a part of the training in the use of the ILPPA, questions and concerns were addressed and discussions were conducted regarding how to best assess specific tasks. Examples and particular case studies were deliberated. 
Initially, rehabilitation teachers met with program participants in their homes to gather demographic information and conduct the pre-program assessment related to levels of performance and independence on the 41 tasks. The performance and independence ratings were determined from a combination of techniques including interview, observation, and demonstration. In the end, each rehabilitation teacher's professional judgment was the primary basis for assessment. In order to improve inter-observer reliability, pre and post assessments for any one particular consumer were completed by the same rehabilitation teacher at program beginning and end. Once the pre-program ILPPA was completed, it was forwarded to the RRTC-BLV for inspection and data entry. The post-program ILPPA was administered at the completion of the consumer's independent living program. Thus, post-program ILPPA ratings were conducted without reference to the pre-program ratings. Once completed, the post-program ILPPA was also returned to the RRTC-BLV for inspection and data entry.

\section{Data Analysis}

Descriptive data on the population studied were compiled and reported. These data encompassed participant characteristics, environmental conditions, and the types of services provided. The participant characteristics reported included: age, sex, marital status, housing arrangement, number of individuals living in the immediate household, the degree of vision loss, the existence of non-visual impairments, the number of referrals made to other service providers, and specific categories of services provided.

To answer the four research questions proposed in this study, pretest and posttest composite scores were calculated and compared. Composite scores were determined for each of the three age categories in relation to ADL performance, ADL independence, IADL performance, and IADL independence. Pretest and posttest scores on performance and independence were compared by age category.

One concern related to the ILPPA was that it did not require that a rehabilitation teacher rate the level of performance on every task, allowing a response option of "unable to obtain a reliable rating". Such an option was not available when rating levels of independence. Because this option could possibly skew a participants composite ADL or IADL performance score, a scheme was developed to control for any such "missing data" in order to prevent it from impairing the integrity of a composite score. SPSS was programmed to compute ADL and IADL scores only for participants who did not exhibit missing data on more than two individual tasks scores. In other words, more than half of the tasks comprising the ADL or IADL domain had to be free of missing data in order to be included in the computation of composite scores. As a result, participants ADL and IADL scores that were considered in this analysis were comprised of at least three of the five tasks identified as ADL, and four of the six tasks identified as IADL. For this reason the number of cases per statistical analysis varied slightly from the total $\underline{\mathrm{N}}$ of 1,194 . The $\underline{\mathrm{n}}$ 's for the dependent variables were ADL performance and ADL independence $\underline{\underline{n}}=1,154$, and IADL performance and IADL independence $\underline{\underline{n}}=1,152$.

A doubly multivariate analysis of variance (MANOVA) repeated measures design incorporating a two between groups' variables (age category and "Program" (confounded with state)) was computed to assess the statistical significance of differences between pretest and posttest scores. A significance level of $\mathrm{p}<.05$ was chosen. The "Program" factor was included in order to mitigate the variability among the six states from which the data were collected and thereby increase the accuracy of the analysis by keeping the experimental errors as small as possible.

Four attendant analyses of variance (ANOVA) were computed to further investigate significance across each of the four dependent variables. This procedure allowed for an analysis of the distribution of variance between the independent variable of age (defined at three levels) as applied to each of the four dependent variables of ADL performance, ADL independence, IADL performance, and IADL independence. Because experiment wise error rates multiply rapidly with an increase in the number of comparisons, significance levels of $p<.0125$ were chosen for each of these analyses in order to help avoid Type I errors.

\section{Results}

During FY: 95-96 a total of 1,558 individuals aged 65 or older were involved in the VII-2 independent living programs conducted within the six states that comprise the database for this study. Seventy-seven percent of those involved in the VII-2 programs fully completed the services provided during this period of time. Pretest and posttest assessment date were available from each of the 1,194 individuals who successfully completed their programs. The number of successful program participants per state for which data were analyzed were as follows: Arkansas, 377; Georgia, 32; Idaho, 104; Kentucky, 16; Tennessee, 110; and Virginia, 555.

The age range of program participants was 65 to 99 years. The median age was 80 , and the mean and modal age was 81 . The breakout of participants by age group was as follows: 65 to 74,25 percent $(\underline{n}=300) ; 75$ to 84,48 percent $(\underline{n}=570)$; and 85 and above, 27 percent $(\underline{n}=324)$ (see Table 1). 
Overall, 73 percent of program participants were female, a ratio that increased progressively by age category. Sixty-nine percent of program participants were unmarried at the time of their participation in the program; the vast majority among them were widowed. Fifty-two percent lived alone, a ratio that increased by age category. Forty-three percent lived with only one other individual. The available participant descriptive data are provided in Table 1.

Table 1. Participant Descriptive Data

\begin{tabular}{|c|c|c|c|c|c|c|c|c|}
\hline \multirow[t]{3}{*}{ Data Category } & \multirow{3}{*}{$\begin{array}{l}\text { Age I } \\
65-74 \\
\text { freq. }\end{array}$} & \multirow[b]{3}{*}{$\underline{\%}$} & \multirow{2}{*}{\multicolumn{2}{|c|}{$\begin{array}{l}\text { Age II } \\
75-84\end{array}$}} & \multirow{2}{*}{\multicolumn{2}{|c|}{$\begin{array}{l}\text { Age III } \\
85+\end{array}$}} & \multicolumn{2}{|c|}{ All Ages } \\
\hline & & & & & & & & \\
\hline & & & freq. & $\underline{\%}$ & freq. & $\underline{\%}$ & freq. & $\underline{\%}$ \\
\hline All Participants & 300 & 25 & 570 & 48 & 324 & 27 & 1194 & 100 \\
\hline \multicolumn{9}{|l|}{ Sex } \\
\hline Female & 198 & 67 & 421 & 74 & 246 & 76 & 865 & 73 \\
\hline Male & 98 & 31 & 147 & 26 & 76 & 24 & 321 & 27 \\
\hline \multicolumn{9}{|l|}{ Marital Status } \\
\hline Married & 134 & 45 & 166 & 29 & 70 & 22 & 370 & 31 \\
\hline Widowed & 125 & 42 & 354 & 63 & 233 & 73 & 712 & 60 \\
\hline Single/Sep./Div. & 37 & 13 & 43 & 8 & 18 & 5 & 98 & 9 \\
\hline \multicolumn{9}{|l|}{ \# Living in House } \\
\hline Alone & 96 & 33 & 283 & 50 & 169 & 52 & 548 & 51 \\
\hline Participant + 1 & 157 & 54 & 198 & 35 & 108 & 34 & 463 & 43 \\
\hline Participant $+2+$ & 39 & 13 & 89 & 15 & 45 & 14 & 67 & 6 \\
\hline \multicolumn{9}{|l|}{ Residential Setting } \\
\hline Private Residence & 277 & 92 & 496 & 87 & 247 & 76 & 1017 & 85 \\
\hline Supportive Living & 17 & 6 & 61 & 11 & 60 & 19 & 138 & 12 \\
\hline Nursing Care & 6 & 2 & 9 & 2 & 17 & 5 & 32 & 3 \\
\hline \multicolumn{9}{|l|}{ Level of Visual Loss } \\
\hline Total/LP Only & 14 & 7 & 22 & 6 & 13 & 6 & 48 & 6 \\
\hline Legal Blindness & 151 & 72 & 309 & 77 & 176 & 76 & 636 & 76 \\
\hline Visual Impairment & 45 & 21 & 68 & 17 & 42 & 18 & 155 & 18 \\
\hline Non-Visual Disability & 249 & 83 & 461 & 81 & 266 & 82 & 976 & 82 \\
\hline Cardiovascular & 143 & 48 & 279 & 49 & 149 & 46 & 571 & 48 \\
\hline Musculoskeletal & 71 & 24 & 184 & 32 & 98 & 30 & 353 & 30 \\
\hline Digestive & 91 & 30 & 139 & 24 & 85 & 26 & 315 & 28 \\
\hline Hearing & 9 & 8 & 80 & 14 & 80 & 25 & 183 & 16 \\
\hline Diabetes & 67 & 22 & 57 & 10 & 23 & 7 & 147 & 13 \\
\hline
\end{tabular}

Note: This profile includes all VII-2 participants who completed their programs. In categories where small amounts of data are missing, valid percentages are calculated. Some participants reported multiple, non-visual disabilities.

All program participants exhibited a loss of vision to the degree that it interfered with their ability to conduct daily activities in a normal fashion. Legal and/or total blindness was exhibited by 82 percent of those in this study (see Table 1). The majority of participants reported multiple disabilities. In addition to visual loss, non-visual disabilities were prevalent among 976, or 82 percent, of the program participants. The five most prominent non-visual disabilities were cardiovascular disease, musculoskeletal disorders, digestive disorders, hearing loss, and diabetes.

Participant characteristics were for the most part similar across the three age categories; however, some variations are worth noting (see Table 1). The percentage of those who were married decreased by age category. Those in the 85 and older category were half as likely to be married (22\%) as those in the 65 to 74 year age group (45\%). The percentage of those living alone increased noticeably with age, 33 percent among those in the age 65 to 74 group compared to 52 percent in the 85 and older group. The percentage of participants residing in a private residence decreased as age increased, dropping from 92 percent in the 65 to 74 year category to 76 percent in the 85 and older category. Hearing loss increased steadily by age category, rising from 8 percent to 25 percent.

Services provided participants in the three age groups were generally similar; however, three variations are worth noting (see Table 2). The 85 and older group included smaller percentages of those receiving low vision devices and those being referred to other agencies for additional services. The percentage of those receiving mobility training was slightly lower among those age 75 and older. The proportions of those receiving independent living skills training, counseling, communication aids, and adaptive devices were relatively stable across all three age groups. 
A multivariate analysis of variance (MANOVA), repeated measures statistical procedure was run to determine the overall significance of gains on the pretest to posttest scores. A "Program" variable (confounded with state) was employed as a factor to reduce the error sums of squares by controlling the variability among the six programs from which the data were collected.

For performance and independence, the main effect of age was significant, $\underline{F}(8,32)=5.52, \underline{p}<.05$ (see Table 3 ). The main effect of the Program (blocking) variable was also significant, $\underline{F}(20,32)=24.02$, $\underline{p}<.05$, which suggests that there were differences in the scores between the programs from which data were collected. There was no significant interaction across age group pre to post scores, $\underline{F}(8,32)=1.39, \underline{p}>.05$. Significance among the Program

variable $\underline{\mathrm{F}}(20,32)=31.86, \underline{\mathrm{p}}<.05$ suggest that there are differences within the programs from which data were collected.

In order to fully address the four research questions, four attendant analyses of variance (ANOVA's) were computed to determine the significance of age specific gains in relation to ADL and IADL performance and independence. To control for experiment wise error rates and avoid Type I errors, significance levels of $\underline{p}<.0125$ were considered appropriate for each of these analyses.

The main effect of age was significant for all four dependent variables: ADL performance, $\underline{\mathrm{F}}(2,1146)=.27, \underline{\mathrm{MSE}}=$ 16.28; ADL independence, $\underline{\mathrm{F}}(2,1146)=5.01, \underline{\mathrm{MSE}}=2.28$; IADL performance, $\underline{\mathrm{F}}(2,1144)=16.20$, $\underline{\mathrm{MSE}}=37.02$; and IADL independence, $\underline{F}(2,1144)=19.55, \underline{\mathrm{MSE}}=11.04 ; \mathrm{p}<.0125$. (see Tables 4-5). There was no significant interaction among age groups pre to post for all four dependent variables: ADL performance, $\underline{\mathrm{F}}(2,1146)=2.86, \underline{\mathrm{MSE}}=$ 3.69; ADL independence, $\underline{\mathrm{F}}(2,1146)=.33, \underline{\mathrm{MSE}}=.83$; IADL performance, $\underline{\mathrm{F}}(2,1144)=2.07, \underline{\mathrm{MSE}}=9.33$; and IADL independence, $\underline{\mathrm{F}}(2,1144)=.92, \underline{\mathrm{MSE}}=$

Table 2. Services Received by Participants

\begin{tabular}{lllllllll}
\hline Service Category & $\begin{array}{l}\text { Age I } \\
\text { 65-74 }\end{array}$ & \multicolumn{3}{c}{$\begin{array}{l}\text { Age II } \\
75-84\end{array}$} & \multicolumn{3}{c}{$\begin{array}{c}\text { Age III } \\
85+\end{array}$} \\
& $\underline{\text { freq. }}$ & $\underline{\underline{\%}}$ & $\underline{\underline{\text { freq. }}}$ & $\underline{\underline{\%}}$ & $\underline{\underline{\text { freq. }}}$ & $\underline{\underline{\%}}$ & $\underline{\text { freq. }}$ & $\underline{\underline{\%}}$ \\
\hline IL Skills Training & 269 & 90 & 502 & 89 & 291 & 90 & 1062 & 90 \\
Counseling & 261 & 88 & 477 & 85 & 278 & 86 & 1016 & 86 \\
Adaptive Devices & 235 & 79 & 437 & 78 & 257 & 79 & 929 & 79 \\
Low Vision Devices & 215 & 72 & 399 & 71 & 208 & 64 & 822 & 69 \\
Communication Aids & 138 & 47 & 267 & 48 & 156 & 49 & 561 & 48 \\
Mobility Training & 101 & 34 & 162 & 29 & 89 & 28 & 352 & 30 \\
Interagency Referral & 184 & 62 & 30 & 57 & 185 & 54 & 699 & 58 \\
One agency & 94 & 32 & 169 & 30 & 106 & 32 & 363 & 31 \\
Two or More & 90 & 30 & 151 & 27 & 77 & 22 & 336 & 27 \\
\hline
\end{tabular}

Table 3. Multivariate Analysis of Variance for Performance and Independence

\begin{tabular}{lll}
\hline Source & df & $\underline{F}$ \\
\hline & Between & groups \\
Program (Block) - Main Effect & 20 & $24.02 *$ \\
Age Group & 8 & $5.52 *$ \\
Constant & 4 & $15626.05 *$ \\
Error & 1119 & $(16.42)$ \\
\hline & Within & groups \\
Program (Block) x Time & 20 & $31.86 *$ \\
& 8 & 1.39 \\
Age Group x Time & & \\
Time & 4 & $39.42 *$ \\
Error & 1119 & $(4.32)$ \\
\hline
\end{tabular}

Note: Values enclosed in parentheses represent mean square errors.

$\mathrm{G}=$ Gains pretest to posttest.

$* \mathrm{p}<.05$.

$3.62 ; \mathrm{p}<.0125$. Means and standard deviations for the dependent variables are reported in Table 6 . 
Results of the study suggest: (a) there were significant improvements in the overall pretest to posttest gains that occurred in performance and independence on ADL and IADL (Tables 3-5, (b) there were no significant interactions across the age groups indicating that age was not a factor in ADL and IADL levels of performance and independence (see Tables 4-5). Based on the Program (blocking) factor, the ANOVA analyses suggest that there were statistically significant differences in the scores both between and within the six programs that contributed to the database.

The research questions in this study were designed to guide an investigation into the changes that occurred for older adults with severe visual impairments who participated in a rehabilitation program designed to increase their independent living skills. In regard to this population and the four research questions, it was determined that:

1). Program participants exhibited statistically significant gains in their level of ADL performance. No significant interactions were determined across the age groups, which indicated that age was not a factor in the ADL performance gains that were observed.

2). Program participants exhibited statistically significant gains in their level of ADL independence. No significant interactions were determined across the age groups, which indicated that age was not a factor in the ADL independence gains that were observed.

Table 4. Analysis of Variance for Activities of Daily Living (ADL)

\begin{tabular}{llll}
\hline & & $\underline{F}$ & \\
\cline { 2 - 4 } Source & $\mathrm{df}$ & Performance $(\mathrm{G})$ & Independence $(\mathrm{G})$ \\
\hline & Between & groups & \\
Program (Block) - Main Effect & 5 & $76.61^{*}$ & $58.15^{*}$ \\
Age Groups & 2 & $.27 *$ & $5.01 *$ \\
Within \& Residual & 1146 & $(16.28)$ & $(2.28)$ \\
\hline & Within & groups & \\
Program (Block) x Time & 5 & $32.61^{*}$ & $130.79 *$ \\
Age Group x Time & 2 & 2.86 & .33 \\
Time & 1 & $43.76^{*}$ & $38.31^{*}$ \\
Within \& Residual & 1146 & $(3.69)$ & $(.83)$ \\
\hline
\end{tabular}

Note: Values enclosed in parentheses represent mean square errors.

$\mathrm{G}=$ Gains pretest to posttest.

$* \underline{p}<.0125$.

Table 5. Analysis of Variance for Instrumental Activities of Daily Living (IADL)

\begin{tabular}{llll}
\hline & & $\underline{\mathrm{F}}$ & \\
Source & Between & groups & \\
\hline & 5 & $26.44^{*}$ & $13.38^{*}$ \\
Program (Block) - Main Effect & 2 & $16.20 *$ & $19.55^{*}$ \\
Age Groups & 1144 & $(37.02)$ & $(11.04)$ \\
Within \& Residual & Within & groups & \\
\hline & 5 & $12.16 *$ & $51.19 *$ \\
Program (Block) x Time & 2 & 2.07 & .92 \\
Age Group x Time & 1 & $43.76 *$ & $38.31 *$ \\
Time & 1144 & $(9.33)$ & $(3.62)$ \\
Within \& Residual & & & \\
\hline
\end{tabular}

Note: Values enclosed in parentheses represent mean square errors.

$\mathrm{G}=$ Gains pretest to posttest.

$* \mathrm{p}<.0125$. 
Table 6. Pretest and Posttest Composite Means and Standard Deviations

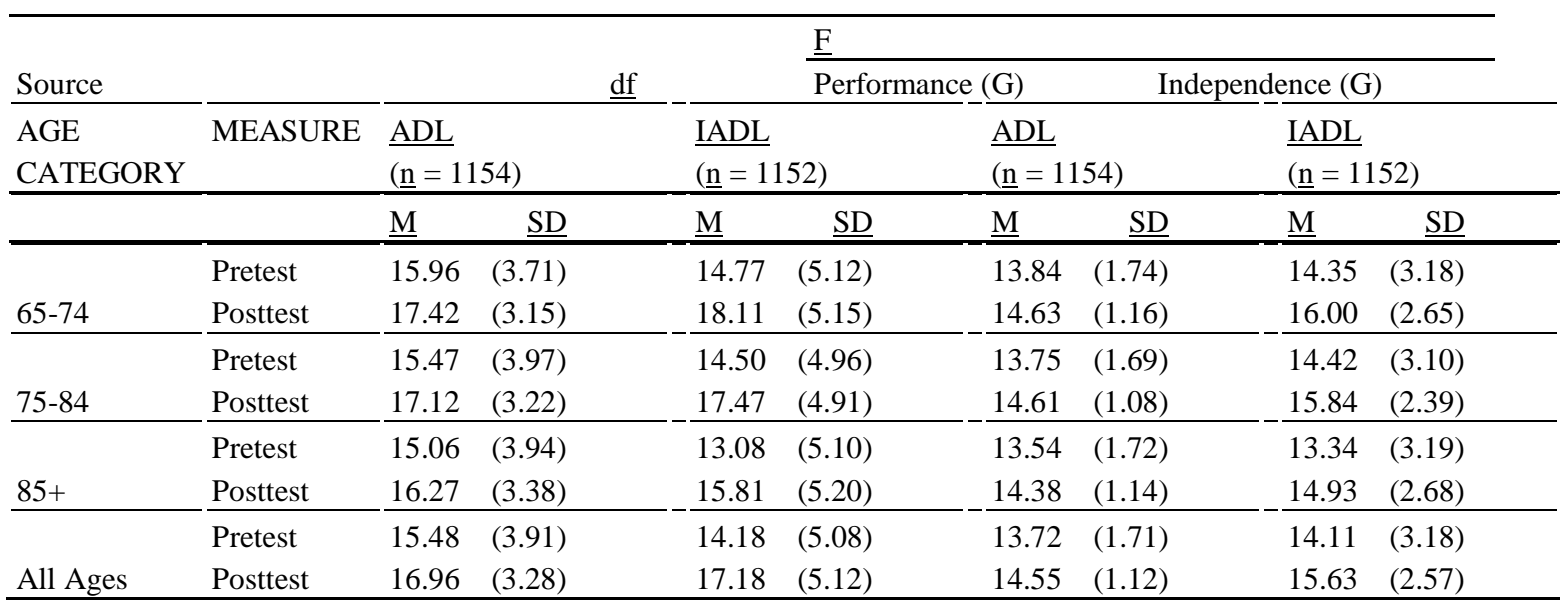

Note: Performance is rated on a four point scale and independence on a three point scale. Scores for ADL are a composite of an assessment of five tasks and IADL a composite of an assessment of six tasks.

3). Program participants exhibited statistically significant gains in their level of IADL performance. No significant interactions were determined across the age groups, which indicated that age was not a factor in the IADL performance gains that were observed.

4). Program participants exhibited statistically significant gains in their level of IADL independence. No significant interactions were determined across the age groups, which indicated that age was not a factor in the IADL independence gains that were observed.

\section{Discussion}

The study resulted in three primary findings: (a) program participants exhibited statistically significant gains on their overall levels of performance and independence, (b) statistically significant gains in performance and independence were demonstrated within both ADL and IADL, and (c) age group differences were not a significant factor in the improvements observed. Secondarily, based on the use of the state programs as the block variable, it was determined that there were significant differences in levels of performance and independence both between and within the six programs which provided assessment data for this study.

The results of this study suggest that rehabilitation programs designed to improve the independent living skills of older adults who are visually impaired had an overall effect for the better. The positive gains in performance and independence were significant for all ages. No significant differences were observed in the gains across the three age categories.

There were a number of limitations related to this study. Most of these limitations were those inherent in an ex post facto study. The most apparent limitations were: (a) program participants represented a limited population (those served in six state programs), (b) there was no control group to compare outcomes with the treatment group, (c) posttest data on consumers who did not complete the program were not available for purposes of comparison, (d) rehabilitation teachers who provided participant assessment data have an inherent interest in the success of their consumers and are subject to associated observer biases, and (e) limitations inherent in the ILPPA, the instrument used to measure levels of performance and independence, were unavoidable.

The limitation of greatest concern to the researcher was observer bias. Because rehabilitation teachers have a vested interest in the positive outcomes of their consumers, errors of leniency or phenomenon such as the halo effect may skew assessments in a positive direction. This limitation should be addressed in future studies because the effects of this limitation could potentially account for the gains observed.

One notable limitation of the ILPPA relates to consumer intention. Although the ILPPA is useful for discerning various levels of dependence, independence, and interdependence, one of the shortcomings of the instrument is that it cannot discern self-induced dependencies (Baltes, 1996). Therefore, the ILPPA cannot explain why various patterns of dependence exist. In future studies, it would be useful to ascertain differences between dependencies that are forced and those that are self-induced based upon intentionality.

Overall, the levels of improvement on performance and independence within the IADL domain were almost double that of the ADL domain (see Table 6). It is not known if these differences are related to: (a) the types of tasks that comprise 
these domains, (b) the emphasis in the particular independent living programs, (c) the differences in pretest levels at which participants begin their programs, or (d) other factors yet to be identified. Further study in regard to such differences is warranted.

The results of this study corroborate the findings of Sheets et al. (1994) that rehabilitative interventions which include personal aids, devices, and environmental modifications can be effective in lessening the task limitations imposed by some disabilities. More specifically, this study adds visual impairment to the list of disabilities for which task limitations can be mitigated through adaptive intervention.

Burnette and Mui (1994) discovered that predictors of depressive symptoms include greater levels of impairments on ADL and a decreased sense of control. Because the current study has documented positive changes among participants on overall levels of ADL functioning, further investigation needs to be conducted to determine if such improvements might also be related to one's sense of control and, consequently, help decrease depressive symptoms.

An area of interest not investigated by this study was the degree to which rehabilitation programs help participants achieve gains on tasks specifically identified as critical for adjustment to blindness. Three tasks in this study that were associated with IADL have been previously identified as tasks critical for adjustment to blindness (Orr, 1992). These tasks, managing money, using the telephone, and preparing meals, demonstrated the highest levels of improvement on both performance and independence in this study. Additional tasks on the ILPPA which go beyond the scope of ADL and IADL parameters and are considered important for adjustment to blindness include: accessing printed materials, accessing scripted materials, orientation and mobility, effective use of low vision devices, matching clothes, taking notes, corresponding, accessing a computer, telling time, and general communication in a sighted world. Several tasks on the ILPPA could be aggregated to investigate changes that occur within an "adjustment to blindness" domain. These tasks also deserve further investigation.

Many questions regarding the effectiveness of these rehabilitative interventions are beyond the scope of this study. What makes a program helpful for some and not helpful for others may be highly individualized. Some elements of rehabilitation programs are more difficult to quantify than others. Studies need to be conducted that investigate the affects of some of the more detailed aspects of these rehabilitation programs. The affects of these programs on the overall psychosocial well-being of participants need to be investigated.

It is still unclear what factors are most significant in determining the degree of improvement that a participant achieves related to daily living activities. It is hoped that this study will be a springboard to raising and answering additional questions, which will ultimately provide a clearer picture of the relationships between the many yet to be identified variables which contribute to maintaining personal independence.

In summary, older adults with severe visual impairments who participated in rehabilitation programs designed to increase their independent living skills did demonstrate significant pretest to posttest gains in their levels of performance and independence. Although overall scores on the four criteria generally decreased with increases in age, there was no evidence that age was a factor in the gains that were observed in performance and independence among the ADL and IADL tasks.

\section{Implications}

The findings from this study bring new information to the literature regarding the outcome of rehabilitative interventions designed to increase the independent living skills of older adults who are blind. Significant gains were documented on both performance and independence across the ADL and IADL domains. At the same time, there was no evidence that age differentially affected the gains that were observed.

The results of this investigation illustrate that rehabilitative interventions can be effective in promoting independent living among older adults of all ages. Older adults as a group tend to experience increasing health problems, many of which do not respond well to medical interventions. Non-medical rehabilitative interventions, such as those central to the VII-2 independent living programs, focus on adaptive methods and devices as a strategy for maintaining independence. This study provides evidence that non-medical rehabilitative interventions can be effective in improving ADL and IADL performance and independence.

With the onset of multiple disabilities, the loss of a spouse, and the circumstance of living alone, simply maintaining one's level of independent functioning may become a challenge for many older Americans. By definition, extending one's ability to function free of ADL deficits over time extends active life expectancy. To the degree that rehabilitation programs are able to help consumers maintain independent ADL performance, they help consumers extend their active life expectancy. For some older adults who have limited and vulnerable support systems, avoiding premature dependencies may reduce the need for costly assisted living arrangements or long-term residential care. 
Some ADL and IADL tasks have also been identified in the literature as critical for adjustment to blindness (Orr, 1992). The degree to which these rehabilitation programs help participants improve on tasks specifically identified as critical for adjustment to blindness may be an equally important area of study. The daily tasks evaluated which proved to improve with rehabilitative intervention may vary in importance from one participant to another. For this reason, future studies may wish to consider the relative importance of particular tasks that are assessed.

Many older adults display remarkable resilience in the face of difficult circumstances. The factors that influence how well or how poorly one rebounds from disability and other late-life losses are not fully known. Factors affecting how one responds to disability may include: sex, the degree of vision loss, the presence of additional disabilities, the immediate environment, and the types of services received. Further investigation into the factors that contribute to late-life independence for individuals with disabilities is warranted.

\section{Recommendations}

In an effort to enhance future research efforts, the following recommendations are offered in regard to further research in the area of rehabilitation and independent living for older persons who are blind. These particular recommendations stem from what the author has learned in the process of conducting this study. Recommendations related to further research include the following:

1). In order to mitigate the major threat to validity, which results from data collected by rehabilitation teachers with a vested interest in participant improvements, future research with this population should employ data collection methods that do not rely on teachers who may potentially bias the ratings of participants' outcomes.

2). More precise instrumentation should be developed that will provide greater reliability and validity for measuring gains on critical daily tasks in order to be able to better discern the types of changes which occur in performance and independence.

3). Additional studies should be conducted that focus on other factors which may affect program outcomes, such as: sex, marital status, and the degree of vision loss, the presence of additional disabilities, the immediate environment, and the types of services received.

4). Longitudinal and/or follow-up studies should be conducted in order to determine the lasting effects of rehabilitative interventions.

5). A qualitative study or a mixed quantitative and qualitative research design is needed to provide data that contributes to a more detailed assessment of rehabilitation program outcomes.

6). To help avoid the limitations inherent in post hoc studies, program sponsors, such as the federal government, should require that field based research efforts be routinely incorporated as a part of the criteria for funding program proposals.

\section{References:}

Aiken, L. R. (1995). Aging: An introduction to gerontology. Thousand Oaks, CA: Sage Publications.

Baltes, M. M. (1996). The many faces of dependency in old age. New York: Cambridge University Press.

Bandura, A. (1977). Self-Efficacy: Toward a unifying theory of behavioral change. Psychological Review, 84, 190-215. http://dx.doi.org/10.1037/0033-295X.84.2.191

Beach, J. D., Robinet, J. M., \& Hakim-Larson, J. (1995). Self-esteem and independent living skills of adults with visual impairments. Journal of Visual Impairment and Blindness, 89(6), 531-540.

Borg, W. R. \& Gall, M. D. (1989). Educational research: An introduction. New, NY: Longman.

Burnette, D. \& Mui, A. D. (1994). Determinants of self-reported depressive symptoms by frail elderly persons living alone. Journal of Gerontological Social Work, 22 (1/2), 3-19. http://dx.doi.org/10.1300/J083V22N01_02

Cancienne, J. C. (1989). Evaluating programs for independent living services for older blind persons: Factorial structure and reliability of a measure of functional abilities. Unpublished master's thesis, Mississippi State University.

Cox, H. G. (1996). Later life: The realities of aging (4th ed.). New Jersey: Simon \& Schuster.

Crews, J. E. (1991). Measuring rehabilitation outcomes and the public policies on aging and blindness. Journal of Gerontological Social Work, 17 (3-4), 137-151. http://dx.doi.org/10.1300/J083v17n03_11

Crews, J. E. (1994). The demographic, social, and conceptual contexts of aging and vision loss. Journal of the American Optometric Association, 65, 63-68. 
DiStefano, A. F., \& Aston, S. J. (1986). Rehabilitation for the blind and visually impaired elderly. In S. J. Brody \& G. E. Ruff (Eds.). Aging and rehabilitation: Advances in the state of the art (pp. 203-217). New York: Springer Publishing Company.

Furner, S. E., Rudberg, M. A., \& Cassel, C. K. (1995). Medical conditions differentially affect the development of IADL disability: Implications for medical care and research. The Gerontologist, 35, 444-450. http://dx.doi.org/10.1093/geront/35.4.444

Hooyman, N. R., \& Kiyak, H. A. (1993). Social gerontology: A multidisciplinary perspective (3rd ed.). Massachusetts: Allyn and Bacon.

Katz, S. (1983). Assessing self-maintenance: Activities of daily living, mobility and instrumental activities of daily living. Journal of the American Geriatrics Society, 31, 721-727.

Katz, S., \& Stroud, M. W. III (1989). Functional assessment in geriatrics: A review of progress and directions. Journal of the American Geriatrics Society, 37, 267-271.

Kemp, B., Brummel-Smith, K., \& Ramsdell, J. W. (Eds) (1990). Geriatric Rehabilitation. Massachusetts: Little, Brown, and Co. http://dx.doi.org/10.1097/00013614-199007000-00012

Kline, D. W., \& Schieber, F. (1985). Vision and aging. In J. E. Birren \& K. W. Schaie (Eds). Handbook of the psychology of aging (2nd ed. pp. 296-331). New York.: Van Nostrand Reinhold.

Lawton, M. P. (1991). Functional status and aging well. Generations, XV(1), 31-35.

Mann, W. C., Hurren, D., Tomita, M., \& Charvat, B. A. (1995). The relationship of functional independence to assistive device use of elderly persons living at home. The Journal of Applied Gerontology, 14, $225-247$. http://dx.doi.org/10.1177/073346489501400206

Motenko, A. K., \& Greenberg, S. (1995). Reframing dependence in old age: A positive transition for families. Social Work, 40, 382-390.

Nieuwenhuijsen, E. R., Frey, W. D. \& Crews, J. E. (1991). Measuring small gains using the ICIDH severity of disability scale: Assessment practice among older people who are blind. International Disability Studies, 13, $29-33$. http://dx.doi.org/10.3109/03790799109166679

Orr, A. L. (Ed.) (1992). Vision and aging: Crossroads for service delivery. New York: American Foundation for the Blind.

Sheets, D., Wray, L., and DeJong, F. (1994). Physical and Occupational Therapy in Geriatrics, 12(4), 1-12. http://dx.doi.org/10.1080/J148v12n04_01

Stephens, B. C. (1996). Independent Living Services for Older Individuals Who are Blind: Title VII, Chapter 2 Annual Report for FY:95. Rehabilitation Services Administration. Washington, DC: U.S. Government Printing Office.

Zarit, S. H. (1992). Psychological aspects of aging and visual impairment. In A. L. Orr (Ed.). Vision and aging: Crossroads for service delivery. (pp. 93-118). New York: American Foundation for the Blind.

Zola, I. K. (1993). Disability statistics: What we count and what it tells us. Journal of Disability Policy Studies, 4, 96-107. http://dx.doi.org/10.1177/104420739300400202

Zambelli-Weiner, A., Crews, J. E., \& Friedman, D. S. (2012). Disparities in Adult Vision Health in the United States. American Journal of Ophthalmology, 154(6), 23-30. http://dx.doi.org/10.1016/j.ajo.2012.03.018 